(C)2007 IEEE. Personal use of this material is permitted. However, permission to reprint/republish this material for advertising or promotional purposes or for creating new collective works for resale or redistribution to servers or lists, or to reuse any copyrighted component of this work in other works must be obtained from the IEEE. 


\title{
Capacity Enhancement for Aging Distribution Systems using Single Wire Earth Return
}

\author{
P.J.Wolfs, Senior Member, IEEE, N.Hosseinzadeh, Member IEEE and S.T. Senini, Member IEEE
}

\begin{abstract}
Single wire earth return systems, (SWER), are the low cost technology for rural power distribution and have global application. In the Australian setting, voltage regulation is becoming the determining factor for older SWER systems. In long systems, directly connected shunt reactors are used to compensate the effects of line to ground capacitance. The replacement of fixed shunt reactors with controllable reactors provides an opportunity to approximately double the capacity of an aging infrastructure. Three case studies based on the North Jericho system are presented and a range of practical implementation issues are discussed.
\end{abstract}

Index Terms - Inductors, Power Distribution Control Reactive Power Control, Thyristor Applications, Voltage Control

\section{INTRODUCTION}

Single wire earth return systems, (SWER), have been widely installed in Australia over 50 years, [1-2]. This approach is promoted by the World Bank as a lowest cost technology and will find growing applications in bringing supply to the estimated 2 billion persons globally without power, [3]. SWER systems typically supply loads of $100 \mathrm{~kW}$ to $200 \mathrm{~kW}$ scattered over a line length that might exceed $300 \mathrm{~km}$. The distribution voltage studied in this case is $19.05 \mathrm{kV}$, the phase voltage for a $33 \mathrm{kV}$ three phase systems. Consumer transformers, as shown in Figure 1, are typically $10 \mathrm{kVA}$ to $50 \mathrm{kVA}$ for a standard connection.

In Queensland, a SWER task force has been established to investigate the load growth issues faced by these aging systems. An important option is to apply new technologies into aging SWER systems to release capacity for load growth. Power electronic solutions to SWER problem have been proposed, [4-5]. Distributed generation could also be added, [6-7]. These solutions are more technically complex but are certainly achievable. Central Queensland University has been examining methods applying controlled reactors as an intermediate approach to improving SWER systems at a lower capital cost, $[8,9]$.

This work is supported by the Australian Research Council Grant Number LP0560627 and Ergon Energy Pty. Ltd.

P..J.Wolfs, N.Hosseinzadeh and S.Senini are with the Faculty of Sciences Engineering and Health at Central Queensland University, Rockhampton, 4701 Australia. (email: p.wolfs@cqu.edu.au; n.hossein@cqu.edu.au; s.senini@cqu.edu.au )

\section{CONTROLLABLE SHUNT REACTORS}

Many long SWER systems include shunt reactors to control the effects of the line charging capacitance. In SWER systems this Ferranti effect so pronounced as to make it difficult to maintain the consumers supply within the acceptable regulation range. The line charging current without reactors may be as high as twice the SWER system supply (isolation) transformer rating. Earth designs and unbalance imposed on the three-phase supply network are additional factors.

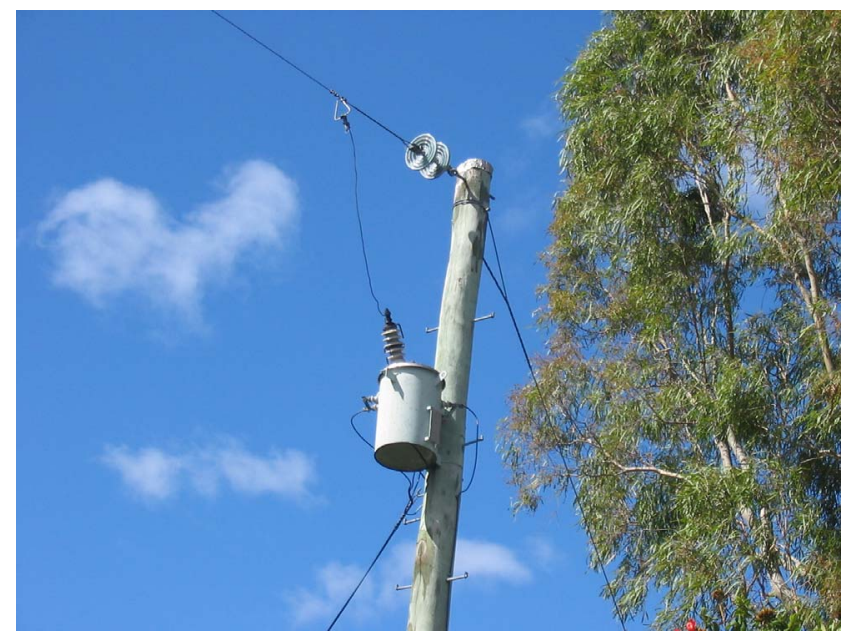

Fig 1. A SWER Customer Transformer, [8].

The industry has always recognized the immediate advantages in removing the reactors at higher loads. While the reactors are small, typically $25 \mathrm{kVAr}$ or $1.3 \mathrm{~A}$ at $19.05 \mathrm{kV}$, a switchable reactor will require a motorized high voltage switch, a voltage transformer and a suitable control element. The switch and the voltage transformer costs are much more influenced by the voltage rating than the reactor current. The resulting minimum costs are relatively high. An alternative is to switch at lower voltages on a transformer secondary. Consumer transformers of $25 \mathrm{kVA}$ rating are produced in large quantities and are consequently moderately priced. Shunt reactors rated at $19.05 \mathrm{kV}$ can readily be replaced by inductors rated at $480 \mathrm{~V}$ connected across the $240 \mathrm{~V}-0$ $240 \mathrm{~V}$ secondary of a transformer. Three approaches are possible: 
- Thyristor controlled reactors connected via dedicated transformers, first proposed by the author in [8];

- Contactor switched reactors connected via dedicated transformers;

- Contactor controlled reactors at the consumer transformer secondaries.

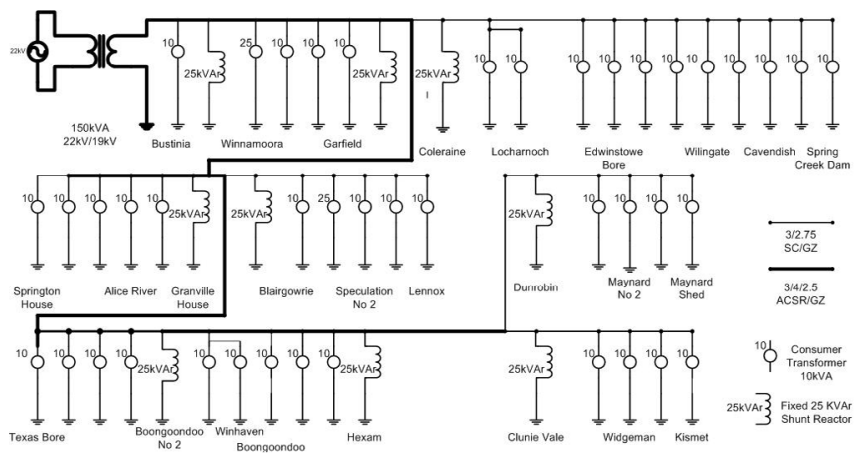

Fig 2. The Jericho North System, [8].

The over-voltage problem occurs at light load when many consumer transformers are lightly loaded. Additional transformer costs and core losses are avoided.

\section{THE JERICHO NORTH POWERSYSTEM}

The paper will show that all approaches can be readily applied to a SWER system and will yield a significant increase in system capacity. The Jericho North system highlights the scale and complexity of a SWER system, [8]. The system is between Barcaldine and Alpha in Central Queensland and simplified schematic is shown in Figure 2, [8]. The transmission voltage is $19.05 \mathrm{kV}$ and system supplies 43 consumer load points. Two load points are $25 \mathrm{kVA}$ and the others $10 \mathrm{kVA}$ giving a total consumer transformer connection of 460kVA. The system isolation supply transformer is rated at $150 \mathrm{kVA}$. Nine $25 \mathrm{kVAr}$ shunt reactors are distributed across the system. The system has $141 \mathrm{~km}$ of backbone conductor, $3 / 4 / 2.5 \mathrm{ACSR} / \mathrm{GZ}$, with $223 \mathrm{~km}$ of lighter spur conductors, $3 / 2.75 \mathrm{SC} / \mathrm{GZ}$. Table one contains the conductor parameters, [8]. Over the $364 \mathrm{~km}$ of conductor the total capacitive loading is $270 \mathrm{kVAr}$.

TABLE I

SINGLE WIRE EARTH RETURN CONDUCTOR PROPOERTIES AT 50Hz

\begin{tabular}{|c|c|}
\hline Conductor & Parameters \\
\hline 3/4/2.5 & R0: $2.02 \Omega / \mathrm{km} ; \mathrm{X} 0: 0.802 \Omega / \mathrm{km}$ \\
ACSR/GZ & B1: $2.086 \mu \mathrm{mho} / \mathrm{km}$ \\
\hline $\mathbf{3 / 2 . 7 5}$ & R0: $12.55 \Omega / \mathrm{km} ; \mathrm{X} 0: 0.819 \Omega / \mathrm{km}$ \\
SC/GZ & B $1: 2.029 \mu \mathrm{mho} / \mathrm{km}$ \\
\hline
\end{tabular}

\section{CONTROLLED REACTOR SYSTEMS}

This paper proposes the substitution of fixed high voltage shunt reactors by controlled reactors. Three options are considered including thyristor controlled reactors as shown as shown in Figure 3, contactor controlled reactors as shown in Figure 4 and consumer transformer connected controlled reactors as shown in Figure 5. In Figure 3 two sequentially controlled units are preferable from a harmonic voltage viewpoint for TCR applications, [8]. To allow a comparison of results, the contactor controlled reactors are similarly split to allow finer voltage control. In the case of the Figure 5, it is necessary to monitor the consumer load current and only apply the reactor load when the transformer capacity is adequate to supply both.

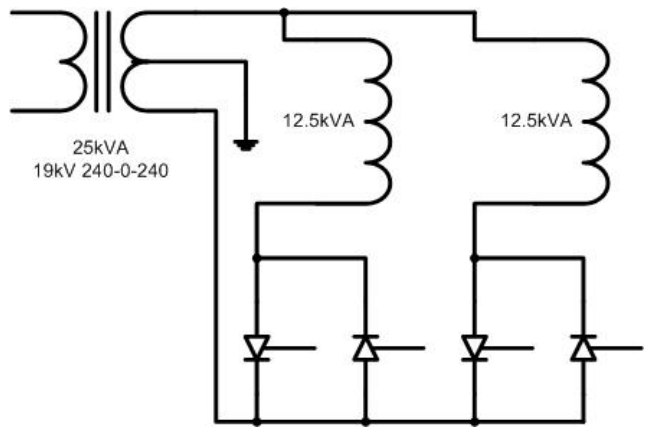

Fig 3. Thyristor Controlled Reactor, [8].

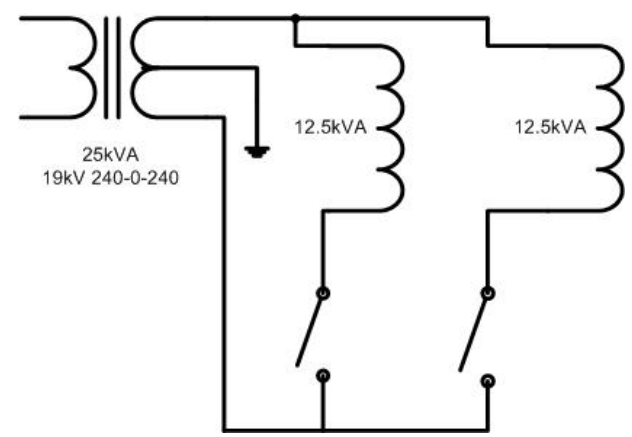

Fig 4. Contactor Controlled Reactor.

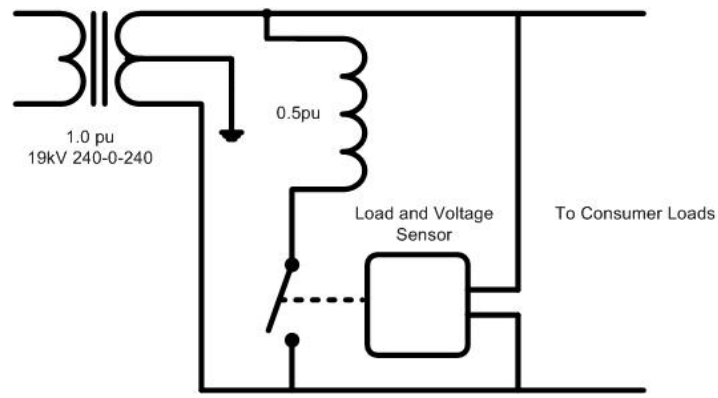

Fig 5. Consumer Transformer Connected Controlled Reactor.

In each case the reactors are controlled to regulate the transformer secondary voltage. This avoids the need to provide a measurement transformer to monitor the high voltage system. The set points and control methods must be adjusted to compensate for transformer reactance and voltage drop under the loads imposed by the reactors. The true RMS voltage at the transformer secondary was determined by squaring the voltage and detecting the mean with a second order low pass filter with poles at 10r/s. 
This delay was important in terms of system stability. For the thyristor controlled reactor a proportional integral control action is used with the following gain settings:

- Proportional Gain: A voltage error of 500Vrms referred to the $19.05 \mathrm{kV}$ system, yields rated inductor current;

- Integral Gain: A voltage error integral of $500 \mathrm{Vrms}$ seconds, referred to the $19.05 \mathrm{kV}$ system, yields rated inductor current.

For the contactor switched reactors hysteresis control was used with the following set points:

- Connection of the first inductor occurs when the secondary voltage rises $0.5 \%$ above nominal voltage, the second inductor stage is connected if the voltage exceeds nominal voltage by $1 \%$;

- Disconnection of the second inductor stage occurs when the secondary voltage falls $3.0 \%$ below nominal voltage, the first stage disconnects when the voltage falls $3.5 \%$ below nominal voltage.

Each inductor controller has a hysteresis width of $4 \%$ and this is selected to ensure that a switching limit cycle does not occur when an inductor is applied. The coupling transformer impedance is $3.6 \%$. The switching of an inductor with a per-unit rating of 0.5 on the transformer base parameters causes a voltage drop of $1.8 \%$. As this is much less than the hysteresis bandwidth the resulting voltage drop will not then cause the inductor to disconnect. The centre of hysteresis characteristic of the controller needs to be offset to allow for the coupling transformer voltage drop under load.

For the consumer connected controlled reactors the following apply:

- The reactor is rated at $50 \%$ of the consumer's transformer rating and is only applied if the consumer load is less than $50 \%$ of the transformer rating;

- The inductor is applied when the secondary voltage exceeds nominal voltage by $0.5 \%$;

- The inductor is removed if the secondary voltage falls $3.5 \%$ below nominal voltage.

In this case a total of $230 \mathrm{kVA}$ of reactor load was available distributed across 43 transformers. This represents a switched reactor system that is both highly distributed and finely graduated.

\section{SIMULATION STUDIES}

The Jericho North System is studied using time domain simulations with the Matlab Simulink Power Systems Block Set. This is a time domain simulator with both control systems and power electronics modeling capacity. As the controlled reactors can be modeled on a cycle by cycle basis the harmonic performance of the system is observable as is the full range of control behaviors. The simulations are run over five seconds or 250 cycles at $50 \mathrm{~Hz}$ allowing any adverse control interactions to be observed. The model features are:

- The layout follows the construction drawings, 76 line sections are identified and implemented;

- $\pi$ sections are used with a maximum $10 \mathrm{~km}$ length;

- The reactors have a $\mathrm{Q}$ factor of 55;

- The isolation transformer full load voltage ratio is $22 \mathrm{kV}: 19.05 \mathrm{kV}$; It has series impedances of 0.016 per unit resistance and 0.038 per unit reactance; The magnetizing branch resistance and reactance are 100 per unit and 200 per unit respectively;

- The $22 \mathrm{kV}$ system is modeled as a infinite bus;

- Each consumer transformer has per unit resistance and reactance of 0.026 and 0.025 per unit; the magnetising branch resistance and reactance are 100 and 200 per unit respectively; The full load voltage ratio is $19.05 \mathrm{kV}$ to $240-0-240$;

- Consumer loads are linear constant impedance $50 \mathrm{~Hz}$ loads at 0.8 power factor calculated at $240 \mathrm{~V}$.

Base line studies of the existing system are first conducted with the fixed shunt reactors in place. Four loading conditions are studied, these are:

- $\quad$ No connected consumer load;

- Three consumer load cases of 50kVA, $100 \mathrm{kVA}$ and 150kVA.

The loading cases are uniformly distributed over each transformer of the system. The 150kVA load case, for example, corresponds to $32.6 \%$ loading at each consumer transformer. Table 2 reports the system voltages under load. The sites listed are reactor locations ordered according to distance from the point of supply.

At no load the residual effects of the line capacitance elevate the voltages by as much as $2 \%$ above nominal, with points such as Boongoondoo reaching $19.45 \mathrm{kV}$. For comparative purposes a low voltage limit of $-6 \%$ below nominal system voltage, or $17.91 \mathrm{kV}$, is selected for the HV system. For a system load of 150kVA many sites fall below this limit and this is indicated by yellow shading of the affected cells in Table 2. Dunrobin records $17.57 \mathrm{kV}$ or $7.8 \%$ below nominal voltage. System capacity can be estimated by interpolating between the results for $100 \mathrm{kVA}$ and $150 \mathrm{kVA}$ loading to estimate the load resulting in a $6 \%$ drop at the worst point in the network. The location is kismet and the estimated load capacity of the existing SWER system is $115 \mathrm{kVA}$. Controlled reactors are now introduced and load cases run in 50kVA increments from no load to a $250 \mathrm{kVA}$ loading. Table 3 reveals the voltage regulation performance over a range of loading conditions for a TCR based approach. Table 4 reports the results under the same loading conditions for a switched reactor approach. Finally the results achieved for reactors located at the consumer transformer secondaries are shown in Table 5 . 
Significant gains in capacity have been made in every case, much less of the system is below the $-6 \%$ limit at $250 \mathrm{kVA}$ of load than was seen for the original system at 150kVA loading. Spring Creek dam is now the controlling point in terms of voltage regulation. Interpolation for loadings where voltage falls to the $-6 \%$ limit for each case yields:

- $\quad$ TCR case - 208kVA ( $81 \%$ increase);

- Contactor Switched -212kVA (84\% increase);

- Consumer connected reactors - 230kVA (100\% increase)

TABLE 2

SYSTEM VOLTAGES (kV) WITH FIXED REACTORS - NOMINAL VOLTAGE

\begin{tabular}{|c|c|c|c|c|}
\hline \multicolumn{1}{|c}{ Location } & $\begin{array}{c}\text { No } \\
\text { Load }\end{array}$ & $\begin{array}{c}\mathbf{5 0} \\
\mathbf{k V A}\end{array}$ & $\begin{array}{c}\mathbf{1 0 0} \\
\mathbf{k V A}\end{array}$ & $\begin{array}{c}\mathbf{1 5 0} \\
\mathbf{k V A}\end{array}$ \\
\hline Bustinia & 19.33 & 19.07 & 18.83 & 18.59 \\
\hline Garfield & 19.41 & 18.92 & 18.48 & 18.03 \\
\hline Coleraine & 19.40 & 18.85 & 18.37 & 17.87 \\
\hline $\begin{array}{c}\text { Granville } \\
\text { House }\end{array}$ & 19.42 & 18.89 & 18.42 & 17.93 \\
\hline Blairgowrie & 19.43 & 18.82 & 18.30 & 17.72 \\
\hline $\begin{array}{c}\text { Boongoondoo } \\
\text { No 2 }\end{array}$ & 19.45 & 18.83 & 18.28 & 17.71 \\
\hline Hexam & 19.44 & 18.88 & 18.23 & 17.64 \\
\hline ClunieVale & 19.44 & 18.78 & 18.19 & 17.58 \\
\hline Dunrobin & 19.44 & 18.77 & 18.18 & 17.57 \\
\hline
\end{tabular}

The increase for this TCR system, is slightly lower than previously reported for a TCR solution that senses the HV system voltage, [8]. The TCR at Bustina is subject to a relatively small voltage range, $19.34 \mathrm{kV}$ to $19.00 \mathrm{kV}$ or less than $2 \%$ swing, and because of the transformer impedance, $3.6 \%$, this is insufficient to force the TCR reactive power to vary across its entire range. The TCR remains partially in conduction even at $250 \mathrm{kVA}$ loadings. The solution is to relocate this TCR to region of the system with a wider voltage fluctuation to consumer load changes. An interesting feature of the consumer reactor connected solution is a slight over voltage, $19.51 \mathrm{kV}$ or $1.023 \mathrm{pu}$ at Bustina for the $150 \mathrm{kVA}$ load case. This is easily dealt with by consumer transformer tapping as the voltage variation at Bustina is small.

\section{THE DYNAMIC PERFORMANCE OF CONTROLLED REACTOR SOLUTIONS}

The dynamic performances of each reactor control method for a 100kVA load case is shown in Figures 6 to 8. In each case the reactor current is evaluated in an RMS sense each cycle and this is multiplied by the nominal voltage to give reactive power. This approach captures some switching transient current and may overstate reactive power for the first few cycles after switching occurs. As the plot durations are 250 cycles this is a tolerable imperfection. For the TCR system response shown in Figure 6 the proportional aspect of the control responds quickly to reduce the initial over voltage when the system is energised. Fine adjustment by the integral controller action then takes several seconds to occur. Figure 7 shows the responses for switched contactors.
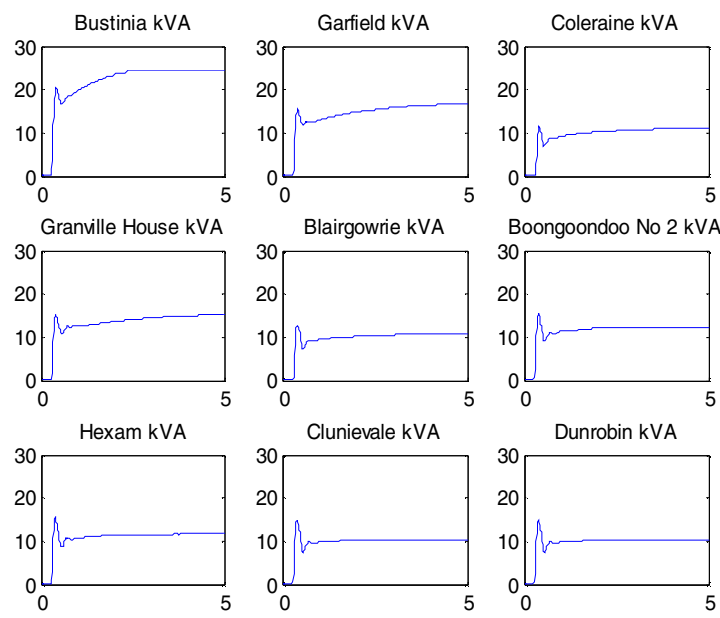

Fig 6. Start Up Reactive Power Responses of TCRs 100kVA Load
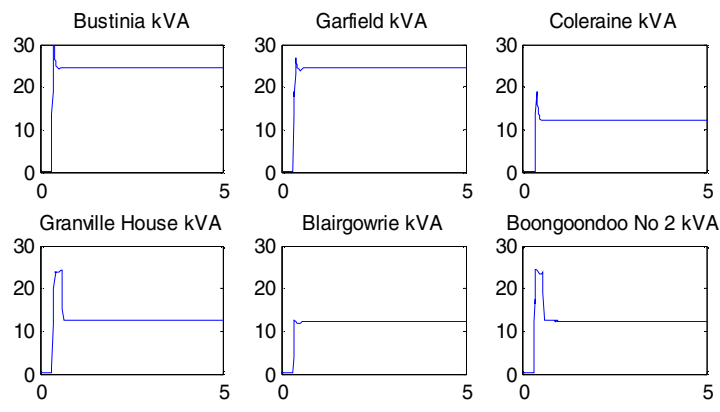

Boongoondoo No 2 kVA
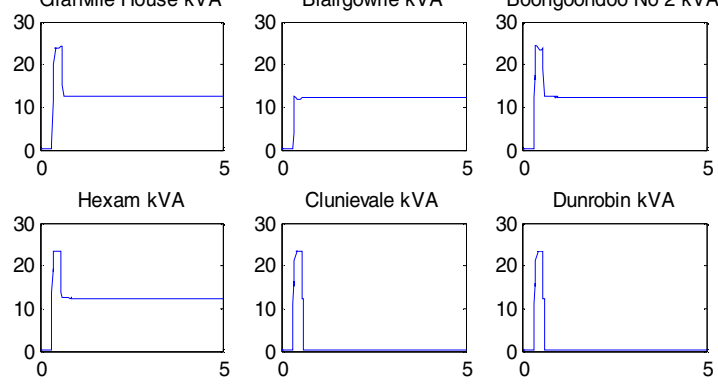

Fig 7. Start Up Reactive Power Responses of Contactor Switched Reactors - 100 kVA Load.

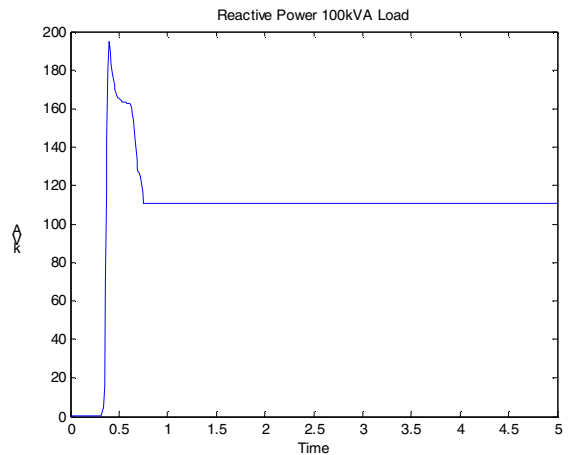

Fig 8. Start Up Reactive Power Responses of Consumer Transformer Switched Reactors - 100 kVA Load. 


\begin{tabular}{|c|c|c|c|c|c|c|}
\hline Location & 0 kVA & $\mathbf{5 0}$ kVA & $\mathbf{1 0 0}$ kVA & $\mathbf{1 5 0}$ kVA & 200 kVA & 250 kVA \\
\hline Bustinia & 19.34 & 19.25 & 19.27 & 19.28 & 19.21 & 19.00 \\
\hline Garfield & 19.39 & 19.15 & 19.05 & 18.84 & 18.74 & 18.33 \\
\hline Coleraine & 19.38 & 19.09 & 18.93 & 18.78 & 18.52 & 18.07 \\
\hline Granville House & 19.40 & 19.14 & 19.02 & 18.89 & 18.66 & 18.22 \\
\hline Blairgowrie & 19.40 & 19.09 & 18.93 & 18.76 & 18.46 & 17.96 \\
\hline Boongoondoo & 19.41 & 19.11 & 18.96 & 18.81 & 18.52 & 18.01 \\
\hline Hexam & 19.40 & 19.10 & 18.94 & 18.80 & 18.48 & 17.95 \\
\hline Clunie Vale & 19.40 & 19.08 & 18.92 & 18.76 & 18.43 & 17.88 \\
\hline Dunrobin & 19.40 & 19.08 & 18.91 & 18.75 & 18.41 & 17.86 \\
\hline
\end{tabular}

Table 3: System Voltages (kV) with Thyristor Controlled Reactors

\begin{tabular}{|c|c|c|c|c|c|c|}
\hline Location & 0 kVA & $\mathbf{5 0}$ kVA & $\mathbf{1 0 0}$ kVA & $\mathbf{1 5 0}$ kVA & 200 kVA & 250 kVA \\
\hline Bustinia & 19.33 & 19.36 & 19.34 & 19.39 & 19.25 & 19.07 \\
\hline Garfield & 19.37 & 19.29 & 19.14 & 19.09 & 18.78 & 18.40 \\
\hline Coleraine & 19.36 & 19.23 & 19.03 & 18.93 & 18.56 & 18.13 \\
\hline Granville House & 19.38 & 19.30 & 19.13 & 19.06 & 18.70 & 18.28 \\
\hline Blairgowrie & 19.37 & 19.27 & 19.06 & 18.93 & 18.50 & 18.02 \\
\hline Boongoondoo & 19.39 & 19.32 & 19.11 & 19.00 & 18.56 & 18.07 \\
\hline Hexam & 19.38 & 19.32 & 19.11 & 18.98 & 18.53 & 18.02 \\
\hline Clunie Vale & 19.38 & 19.31 & 19.09 & 18.95 & 18.47 & 17.95 \\
\hline Dunrobin & 19.38 & 19.31 & 19.08 & 18.94 & 18.54 & 17.92 \\
\hline
\end{tabular}

Table 4: System Voltages (kV) with Contactor Controlled Reactors

\begin{tabular}{|c|c|c|c|c|c|c|}
\hline Location & 0 kVA & $\mathbf{5 0} \mathbf{k V A}$ & $\mathbf{1 0 0} \mathbf{~ k V A}$ & $\mathbf{1 5 0} \mathbf{k V A}$ & $\mathbf{2 0 0} \mathbf{k V A}$ & $\mathbf{2 5 0}$ kVA \\
\hline Bustinia & 19.29 & 19.17 & 19.36 & 19.51 & 19.33 & 19.24 \\
\hline Garfield & 19.32 & 19.04 & 19.16 & 19.23 & 18.86 & 18.67 \\
\hline Coleraine & 19.30 & 18.97 & 19.05 & 19.07 & 18.64 & 18.41 \\
\hline Granville House & 19.34 & 19.02 & 19.13 & 19.20 & 18.78 & 18.59 \\
\hline Blairgowrie & 19.35 & 18.96 & 19.04 & 19.07 & 18.59 & 18.42 \\
\hline Boongoondoo & 19.38 & 18.99 & 19.10 & 19.14 & 18.65 & 18.42 \\
\hline Hexam & 19.40 & 18.98 & 19.10 & 19.13 & 18.61 & 18.37 \\
\hline Clunie Vale & 19.41 & 18.96 & 19.08 & 19.10 & 18.56 & 18.29 \\
\hline Dunrobin & 19.41 & 18.96 & 19.07 & 19.09 & 18.54 & 18.27 \\
\hline
\end{tabular}

Table 5: System Voltages (kV) with Consumer Transformer Connected Controlled Reactors

Initially the system voltage overshoots causing many reactors to connect, especially at the far end of the line. Some then disconnect a few hundred milliseconds later. No further switching actions follow. Figure 8 shows the response with inductors distributed to each consumer load point. In this case the total of all reactor powers is presented. The results are similar with many inductors first connecting in response to the system excitation and over voltage. Reactors towards the far end of the system then disconnect over a few hundred milliseconds.

\section{IMPLEMENTATION ISSUES}

For distribution utilities the implementation issues centre upon system losses, reliability and technical risk. At light load the losses in the reactors and controllers will contribute to the system loss. Systems that require dedicated transformers incur additional core and copper losses. In a TCR system the thyristor conduction losses are higher than the conduction losses in contactors. Table 6 shows the total losses recorded during simulation and are strongly supported by hand calculations of the loss estimates. There are slight differences in the no load voltage profiles for each case and this accounts for the variations. While consumer connected reactors are the most attractive from capital and no load loss standpoints, reactor switching will generate a larger voltage disturbance at the consumer connection point. If switching is limited to a few events each day this should not be a concern.

Jericho North contains nine controlled reactors and contactor switching gives adequate control resolution. If a fewer number of larger reactors are to be employed, and this is a case specific economic issue, continuous control with a TCR 
Table 6: System No Load Losses

\begin{tabular}{|l|l|l|}
\hline System & $\begin{array}{l}\text { No Load } \\
\text { Loss }\end{array}$ & $\begin{array}{l}\text { Incremental } \\
\text { Loss }\end{array}$ \\
\hline HV Fixed Reactors & $12.0 \mathrm{~kW}$ & $0 \mathrm{~kW}$ \\
\hline $\begin{array}{l}\text { Thyristor LV Reactor } \\
\text { Control }\end{array}$ & $20.6 \mathrm{~kW}$ & $8.6 \mathrm{~kW}$ \\
\hline $\begin{array}{l}\text { Contactor Controlled LV } \\
\text { Reactors }\end{array}$ & $20.2 \mathrm{~kW}$ & $8.2 \mathrm{~kW}$ \\
\hline $\begin{array}{l}\text { Consumer Transformer } \\
\text { Secondary Connected } \\
\text { Reactors }\end{array}$ & $14.7 \mathrm{~kW}$ & $2.7 \mathrm{~kW}$ \\
\hline
\end{tabular}

solution might be attractive. The key risk issues are harmonic performance and transformer DC balance. Figure 9 shows that for a TCR, the third harmonic peaks at $38 \%$ of the reactor rated fundamental current at a delay angle, $\alpha=141^{\circ}$. An important feature of the TCR device is that, if driven by a sinusoidal voltage source, $\mathrm{V}_{\mathrm{p}} \sin (\omega \mathrm{t})$, only odd cosine harmonics are present as the current waveform is symmetric around $\omega t=0,[10]$. When several SWER systems are supplied from a shared three phase feeder, considerable harmonic cancellation will occur. For the consumers, the SWER system impedance determines the capacity of the system to absorb harmonic current without excessive voltage distortion. Figure 10 shows the impedance at Dunrobin, a distant point of the system. In this case the $25 \mathrm{kVAr}$ reactors had to be split and sequentially controlled to meet the voltage distortion requirements. Alternative solutions could include the use of passive filters or PWM inductor control.

DC balance is an issue to consider for TCR or any other power electronic solutions. For economic reasons, standard transformers are used to connect the inductors and it is not reasonable to insert air gaps to deal with DC unbalance. Any small firing angle asymmetry, that is difference in the firing angles between the positive and negative half cycles, is capable of producing a current imbalance. The largest volt second unbalance is produced at firing delay angles around $\alpha=90^{\circ}$. A consideration of the volt second area variation caused by a firing asymmetry and the consequent change in the inductor current waveform yields an expression for the DC current of:

$$
I d c=2 \sqrt{2} \times f \times I \text { Ibase } \times \Delta t
$$

where $I d c$ is the DC offset current (A);

$f$ is the fundamental frequency $(\mathrm{Hz})$;

Ibase is the rated current for the inductor (A) and

$\Delta t$ is the firing asymmetry in seconds.

At $50 \mathrm{~Hz}$, a $71 \mu \mathrm{S}$ firing asymmetry produces a DC imbalance of $1 \%$ using the inductor current as a basis. Practical microprocessor based thyristor control system can achieve firings that are symmetric within tens of microseconds. A DC current that is approximately $0.5 \%$ of the inductor current rating could reasonably be expected. The tolerance of the coupling transformers is explored in the experimental results.

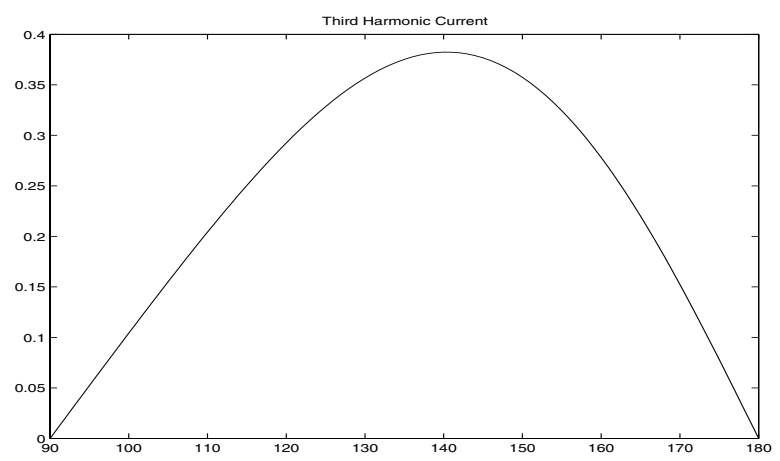

Fig 9. Per Unit Third Harmonic, [8].

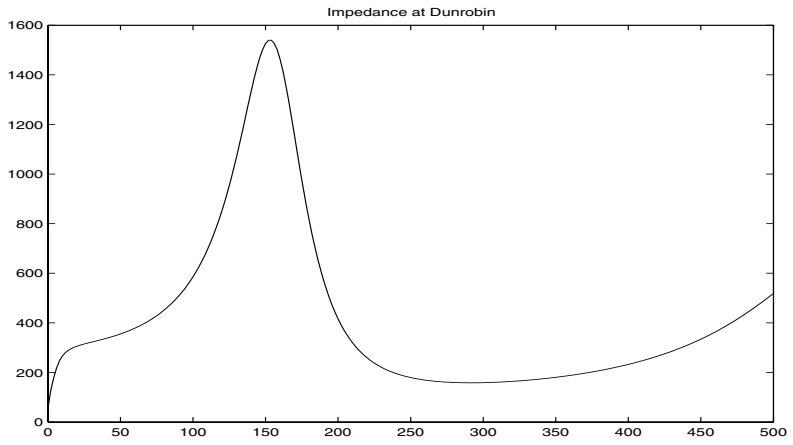

Fig 10. System Impedance, $(\Omega)$, at Dunrobin, $0-500 \mathrm{~Hz},[8]$.

\section{EXPERIMENTAL RESULTS}

A modern 25kVA SWER transformer was subjected to open and short circuit tests. The short circuit impedance, $3.3 \%$, was in line with the values used for the simulation models. The magnetsing current, $0.36 \%$, and core loss, $0.21 \%$, was significantly smaller than expected for the transformers in the relatively old Jericho North system. Significant improvements have occured over the past decade due to the introduction of staggered gap cores. It was noted that the no load current was leading and this is believed to be a consequency of the HV winding self capacitiance. Figure 11 shows an arrangement in which the transformer could be easily subjected to a DC offset current.

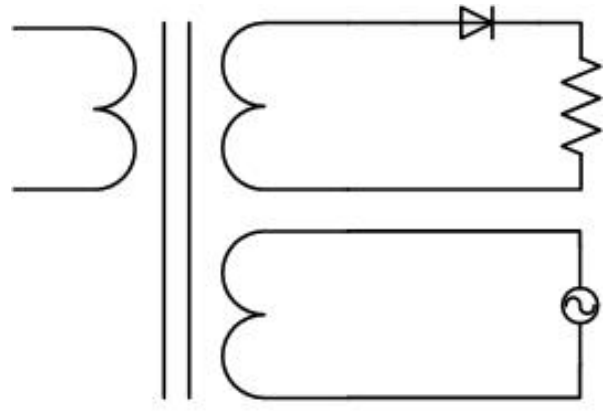

25kVA

19kV 240-0-240

Fig 11. DC Effects on Core Magentisation. 


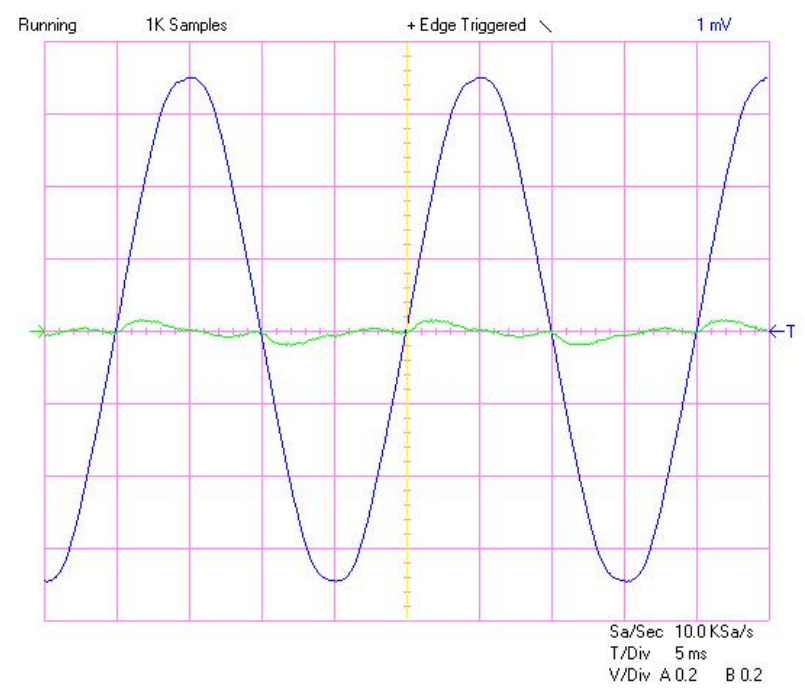

Fig 12. Nominal Core Magentisation Current and Voltage: Current 4A/division; Voltage 100V/division.

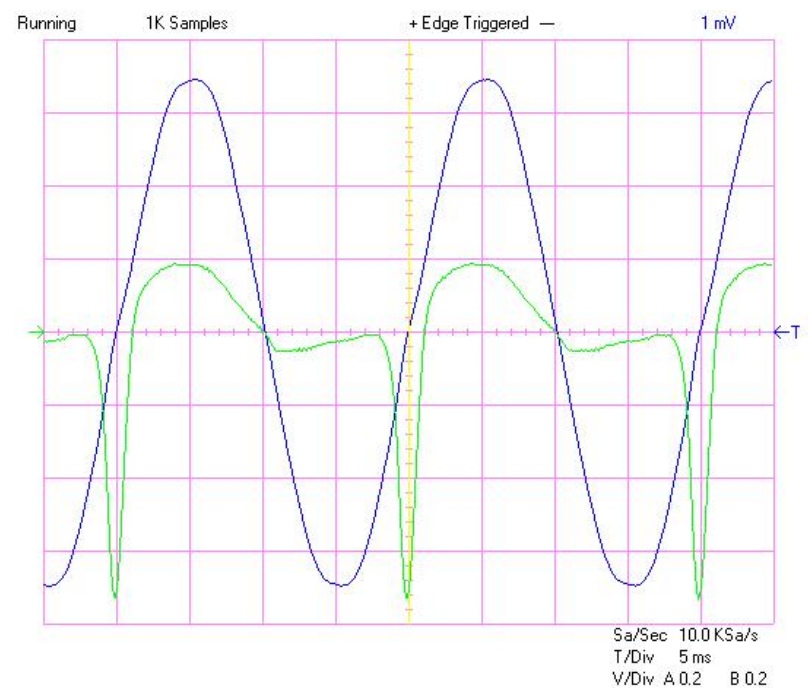

Fig 13. Core Magentisation Current and Voltage with $1.1 \%$ DC Offset: Current 4a/division; Voltage 100V/division.

The transformer was energised using winding one of the two $240 \mathrm{Vac}$ windings. On the second $240 \mathrm{Vac}$ winding, winding two, a diode resistor load was connected. This load generates an easily controlled DC offset. Figure 12 shows the nominal transformer magnetising current when excited from winding one as the green trace with a vertical scale of $4 \mathrm{~A} /$ division. The voltage waveform, on winding two is shown at 100V/division.

In Figure 13 the resulting oscillogram shows the results of connecting a diode plus a $100 \Omega$ resistor load. In this case the DC current $1.1 \mathrm{Adc}$ or $1.1 \%$ on the transformer rating. The expected half cycle peak current is $3.4 \mathrm{~A}$ aligns well with the green trace in the positive half cycle. At end of the negative half cycle a magnetisation current peak of 14A occurs. A minor distortion of the voltage on winding two is visible at the zero crossing. The total transformer losses in this mode of operation, $84 \mathrm{~W}$, was determined by subtracting the input power and the resistor power loss. These losses are quite moderate. Even though the magnetising current waveforms are distorted, and contain a good proportion of second harmonics, the additional losses are not likely to be destructive.

A $25 \mathrm{kVA}$ controlled reactor has been laboratory tested and will move to field tests in 2007 . Figure 14 shows one the two air cooled $12.5 \mathrm{kVA}$ reactors. A quality factor of 55 was achieved which is close to the practical limit for small $50 \mathrm{~Hz}$ reactors with silicon steel cores and copper windings. B-H curve measurements show no appreciable saturation occurs below voltages of $530 \mathrm{Vrms}$ and the core has at least a $10 \%$ margin of tolerance for system over voltages. A steady state surface temperature rise of $30 \mathrm{C}$ was recorded. A hot spot over ambient temperature rise of approximately 50C was measured by a thermocouple placed between the windings and core. The life expectation of the class $\mathrm{H}$ insulation system is beyond 30 years and is appropriate for this application.

Figure 15 shows a voltage control unit which combines with two commercial thyristor phase control units, (one only shown), to form the complete TCR management package. Figure 16 shows a finished contactor controlled reactor system installed in a ground mounted enclosure.

\section{ACKNOWLEDGMENT}

The author gratefully acknowledges the contributions of Anthony Loveday and Jon Turner of Ergon Energy Limited.

\section{CONCLUSIONS}

The replacement of fixed shunt reactors with controlled reactors can considerably increase the capacity of SWER systems. Placement of the reactor on the low voltage side of a conventional transformer allows control to be achieved cheaply with thyristors or contactors. This paper has demonstrated the capacity of this approach to provide a realistic solution for enhancing existing systems.

\section{REFERENCES}

[1] Lloyd Mandeno, "Rural Power Supply Especially in Back Country Areas", Proceedings of the New Zealand Institute of Engineers, Vol 33, Ferguson and Osborn Printers, Wellington, pp 234-271,1947

[2] T.R.Brooking, N.Janse van Rensburg, R.J.Fourie, "The Improved Utilization of Existing Rural Networks with the use of Intermediate Voltage and Single Wire earth Return Systems", IEEE AFRICON '92, pp 228-234, 1992

[3] Allen R. Inversin, "Reducing the Cost of Grid Extension for Rural Electrification", NRECA International, Ltd., World Bank Energy Sector Management Assistance Program, ESMAP, 2000. Available at: http://rru.worldbank.org/Documents/PapersLinks/1072.pdf

[4] S.Thiel, C. Mostert, J.H.R. Enslin, "Universal Power electronic Solution to Low Cost Rural Electrification”, IEEE AFRICON '96 Proceedings, pp 335-340, 1996.

[5] H.C. van Niekerk, I.W. Hofsajer, "The use of series injection to eliminate voltage distortion low and medium voltage networks", IEEE Industrial and Commercial Power Systems Conf., pp1-6, 2000.

[6] M.A.Kashem, G. Ledwich, "Distributed generation as voltage support for single wire earth return systems", IEEE Trans. Power Delivery, Vol. 19, No 3, pp1002-1011., July 2004.

[7] G.Ledwich, "Distributed generation as voltage support for single wire earth return systems", Power Engineering Society General Meeting, Vol 2, pp 2176, 2004. 


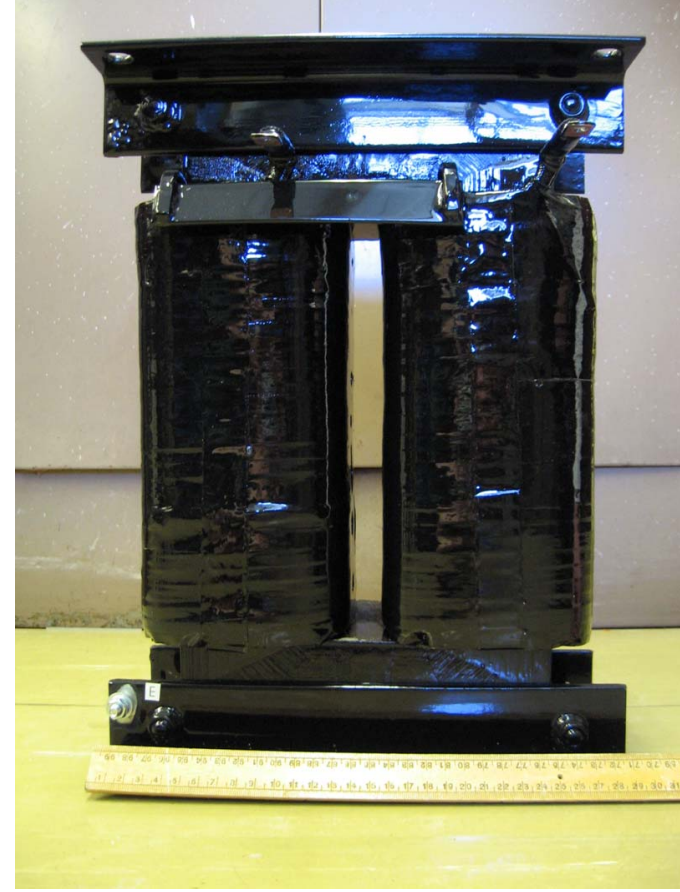

Fig 14. Voltage Control Reactor -12.5 kVA, 480Vrms.

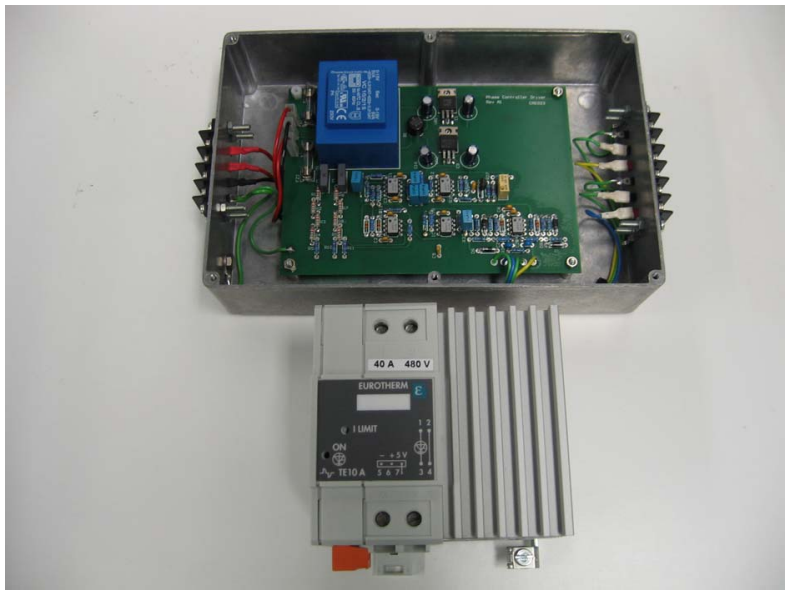

Fig15. Voltage Control System and Commercial 480Vac, 40Arms Thyristor Phase Controller.

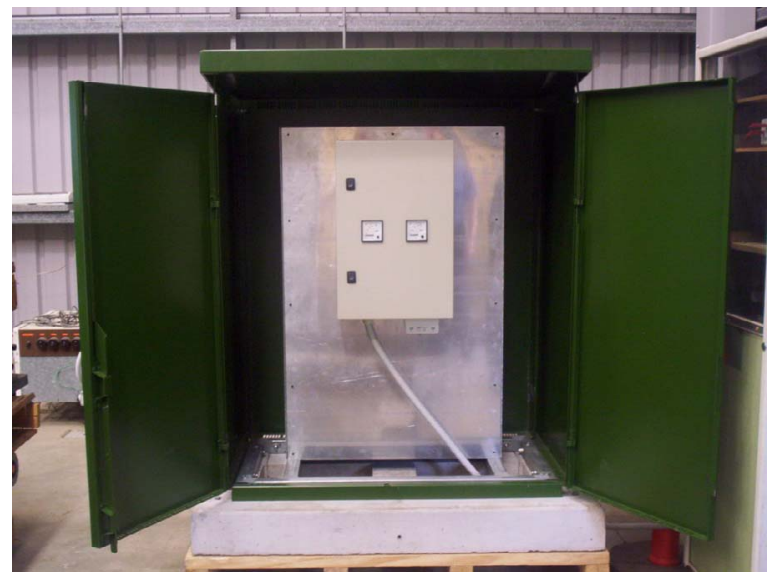

Fig16. SWER Voltage Controlled Reactor System
[8] P.J. Wolfs, "Capacity Improvements for Single Wire Earth Return Systems", IEEE International Power Engineering Conference, Singapore $29^{\text {th }}$ November $-2^{\text {nd }}$ December, 2005.

[9] Peter Wolfs, Steven Senini, Nasser Hossein-Zadeh, Dawit Seyoum, Anthony Loveday, Jon Turner, "Reactor based Voltage Regulator for Single Wire Earth Return Systems", Australian Universities Power Engineering Conference, $11^{\text {th }}-13^{\text {th }}$ December, Melbourne, Australia, 2006.

[10] W.Shepherd, Thyristor Control of AC Circuits. London: William Clowes and Sons Limited, 1975.

\section{BIOGRAPHIES}

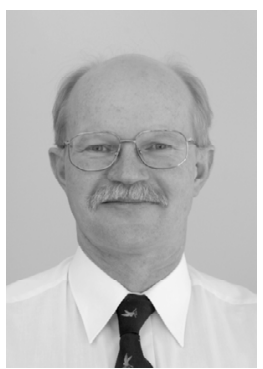

Peter Wolfs (M'80, SM'99) was born in Rockhampton Australia in 1959. He graduated from the Capricornia Institute of Advanced Education in 1980 with a Bachelor of Engineering Degree. He subsequently secured a Master of Engineering degree with the Philips International Institute in the Netherlands in 1981 and a $\mathrm{PhD}$ degree at the University of Queensland in 1992.

$\mathrm{He}$ is the Associate Dean (Research and Innovation) at the Faculty of Sciences, Engineering and Health at Central Queensland University. His special fields of interest include rural and renewable energy supply, electric, solar and hybrid electric vehicles and intelligent systems applications in railways. Professor Wolfs is Senior Member of IEEE, a Fellow of Engineers Australia, a Registered Professional Engineer in the State of Queensland and a member of the Railway Technical Society of Australia.

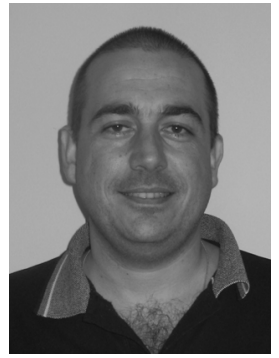

Steven Senini (M'93) was born in Mackay, Australia in 1970. He received the B.Eng. degree with first class honours from Central Queensland University, (CQU), in 1992, a M.Eng in 1995 and his $\mathrm{PhD}$ in 2000. He is currently a Senior Lecturer in Control Systems and Program Coordinator for the Bachelor of Engineering Programs at CQU. His areas of research include engineering education, Single Wire Earth Return distribution systems, railway power systems and power quality. Steven is a member of Engineers Australia, the Australasian Association for Engineering Education and the IEEE.

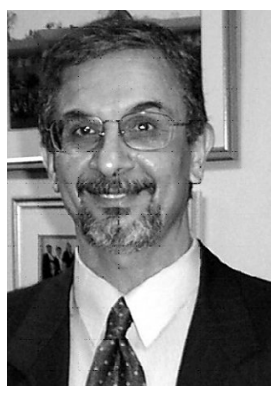

Nasser Hosseinzadeh (M'86) was born in Iran in 1960. He graduated from Shiraz University in 1986 with a Bachelor of Science degree in Electrical and Electronics Engineering. He subsequently received a Master of Science degree from Iran University of Science and Technology in 1992 and a PhD degree in Electrical Engineering from Victoria University in Australia in 1998.

$\mathrm{He}$ is the Electrical Engineering Discipline Leader at the Faculty of Sciences, Engineering and Health at Central Queensland University, Rockhampton, Australia. His special fields of interest include power system analysis and planning, power system stability, fuzzy logic applications in engineering, rural and renewable energy supply, and intelligent system applications in railway engineering. 